\title{
Large scale interaction analysis predicts that the Gerbera hybrida floral E function is provided both by general and specialized proteins
}

\author{
Satu Ruokolainen'1, Yan Peng Ng² , Victor A Albert ${ }^{3}$, Paula Elomaa ${ }^{1}$ and Teemu H Teeri*1
}

\begin{abstract}
Background: The ornamental plant Gerbera hybrida bears complex inflorescences with morphologically distinct floral morphs that are specific to the sunflower family Asteraceae. We have previously characterized several MADS box genes that regulate floral development in Gerbera. To study further their behavior in higher order complex formation according to the quartet model, we performed yeast two- and three-hybrid analysis with fourteen Gerbera MADS domain proteins to analyze their protein-protein interaction potential.

Results: The exhaustive pairwise interaction analysis showed significant differences in the interaction capacity of different Gerbera MADS domain proteins compared to other model plants. Of particular interest in these assays was the behavior of SEP-like proteins, known as GRCDs in Gerbera. The previously described GRCD1 and GRCD2 proteins, which are specific regulators involved in stamen and carpel development, respectively, showed very limited pairwise interactions, whereas the related GRCD4 and GRCD5 factors displayed hub-like positions in the interaction map. We propose GRCD4 and GRCD5 to provide a redundant and general E function in Gerbera, comparable to the SEP proteins in Arabidopsis. Based on the pairwise interaction data, combinations of MADS domain proteins were further subjected to yeast three-hybrid assays. Gerbera B function proteins showed active behavior in ternary complexes. All Gerbera SEP-like proteins with the exception of GRCD1 were excellent partners for B function proteins, further implicating the unique role of GRCD1 as a whorl- and flower-type specific C function partner.

Conclusions: Gerbera MADS domain proteins exhibit both conserved and derived behavior in higher order protein complex formation. This protein-protein interaction data can be used to classify and compare Gerbera MADS domain proteins to those of Arabidopsis and Petunia. Combined with our reverse genetic studies of Gerbera, these results reinforce the roles of different genes in the floral development of Gerbera. Building up the elaborate capitulum of Gerbera calls for modifications and added complexity in MADS domain protein behavior compared to the more simple flowers of, e.g., Arabidopsis.
\end{abstract}

\section{Background}

Reproductive roles of MADS box genes in plants extend from determination of floral organ identity to other floral processes such as control of meristem identity and determinacy, inflorescence architecture, and induction or inhibition of flowering (reviewed in [1]). The current view is that MADS domain regulatory proteins accomplish this multitude of tasks by forming higher order complexes, which then act on promoter sequences of their target

* Correspondence: teemu.teeri@helsinki.fi

1 Gerbera Laboratory, Department of Applied Biology P.O. Box 27 (Latokartanonkaari 7), FIN - 00014 University of Helsinki, Finland

Full list of author information is available at the end of the article genes [2,3]. In the simplest model, the higher order complexes are tetramers, or 'dimers of dimers' $[4,5]$. In this 'floral quartet' model, sepal identity is defined by an AAEE quartet, petals by $\mathrm{ABBE}$, stamens by $\mathrm{BBCE}$ and carpels by a CCEE quartet, the letters referring to functions of the MADS domain proteins in the $\mathrm{ABC}$ and the extended $A B C D E$ models $[4,6,7]$. Other reproductive functions such as meristem identity could be controlled by similar tetramerous complexes in which at least the $\mathrm{A}$ and $\mathrm{E}$ function proteins are thought to participate [8]. However, none of these higher order complexes have been observed or verified in planta, and they could be 
larger and more extensive than tetramers of MADS domain proteins.

MADS transcription factors are highly conserved across the plant kingdom and are easily recognizable by the eponymous MADS domain, named after the first identified members of the gene family [9-13]. The general structure of the best studied type II MADS domain proteins consists of the conserved MADS and the plant-specific $\mathrm{K}$ (keratin-like) domains, which flank the less conserved I (intervening) domain, and the $\mathrm{C}$ (carboxy terminal) domains. All of these protein domains have been shown to be able to participate in dimerization processes. The MADS domain has further DNA binding capacity [14], whereas the variable C domain of some, but not all, MADS domain proteins contains amino acids that function in transcriptional activation $[2,15]$.

The first observed MADS protein dimer was the $\mathrm{B}$ function heterodimer between DEFICIENS and GLOBOSA in Antirrhinum majus [13,16,17]. Many of the protein-protein interactions defined since then are highly conserved among homologs in both monocot and dicot plants [18]. The multimeric protein complexes interact with their target promoter sequences [2,3] by binding to cis elements with the canonical sequence $\mathrm{CC}\left(\mathrm{A} / \mathrm{T}_{6}\right) \mathrm{GG}$, termed the CArG box [10,13,14,16,19-21]. Each MADS protein can participate in a number of different complexes, making the potential number of combinations, and thus target gene sets, very large. Most of the reported protein-protein interactions are between MADS domain proteins themselves, but involvement of other proteins have also been observed. Examples are the anther-specific secreted protein ATA20, the leucine zipper protein MIP1, the seed specific histone fold protein NF-YB, LEUNIG, which shares sequence similarity with yeast Tup1 corepressor, the plant specific regulatory protein SEUSS, and proteins PFMAGO1 and PFMAGO2, which are homologous to highly conserved RNA binding proteins involved in many developmental processes [3,2226]. MADS domain protein complexes have also been shown to act on their own promoters to regulate their own expression, and to form autoregulatory loops that stabilize their expression after induction [16,25,27-36].

We have contributed to floral developmental genetics by investigating a model member of the sunflower family, the ornamental plant Gerbera hybrida (reviewed in [37]). The highly compressed inflorescences (capitula) of the Asteraceae family differ from other model systems in that they bear flowers of dissimilar type, showing differences in sexuality, morphology and sometimes coloration. The different flower types combine in the flower head into a second-order structure resembling a single large flower an apparent pollination adaptation [17,38]. Control of flower and inflorescence development therefore has extra tiers in Gerbera. Not only must the correct floral organs develop in correct places, but also particular types of flowers must emerge along precise radial coordinates of the inflorescence. We have previously shown that many general principles of flower development apply to Gerbera $[37,39,40]$, and that functional homologues for B, C and $\mathrm{E}$ function genes can be identified. However, Gerbera also has its own unique features. Whereas the Arabidopsis thaliana SEPALLATA (SEP) genes encode the E function in a redundant and whorl non-specific manner, among several Gerbera SEP-like MADS box genes, a paralogous pair (GRCD1 and GRCD2) has apparently undergone subfunctionalization, showing non-redundant whorl-specific functions in stamen and carpel development, respectively [41,42]. Interestingly, Gerbera MADS box genes also show differential expression patterns along the radius of the capitulum, suggesting that different complexes may act on flower primordia to engender their different developmental fates [43].

Studies on MADS domain protein higher-order complexes have been carried out in Arabidopsis, snapdragon, Petunia hybrida and tomato [2,3,23,44-46]. Our aim was to map MADS domain protein-protein interactions in Gerbera, and to compare these interactions between Gerbera and other model systems. In this study, a total of fourteen Gerbera MADS domain proteins active (or suspected to be active) in reproductive development were included in an interaction study using yeast two- and three-hybrid assays. These data, in combination with our previous reverse genetics studies, provide intriguing new information for Gerbera MADS domain proteins. Along with the highly specialized E function proteins GRCD1 and GRCD2, Gerbera harbors a redundant pair of $E$ function proteins, GRCD4 and GRCD5, which have an apparently general non-whorl-specific function. Despite functioning as obligate heterodimers [13,19], B function proteins of Gerbera are able to participate in higher order complexes as independent proteins. Furthermore, they have an extensive interaction capacity when present as a dimer. The B function proteins show interaction with $\mathrm{C}$ function proteins and with all Gerbera SEP-like proteins except with staminodia-determining GRCD1. This might indicate a special role for GRCD1 as a whorl- and flowertype specific $\mathrm{C}$ function partner.

\section{Results}

Phylogenetic positioning of Gerbera MADS box genes

Of the tested Gerbera MADS box genes, GSQUA1, GGLO1, GDEF1, GDEF2, GAGA1, GAGA2, GRCD1, $G R C D 2$ and $G R C D 3$ were included in a phylogenetic tree published previously [41] and were placed among orthologous genes from other plant species. The phylogenetic placements of GRCD1 and GRCD2 was further refined by Zahn et al. [47], who showed them to be more distantly related paralogs than previously suspected. GRCD4 and 
GRCD5 (and the above genes) were added to the data set of Zahn et al. [47] and phylogenetic results show them to be related to other SEP-like genes (Additional file 1, Figure S1). The phylogenetic position of Gerbera SQUAMOSA/APETALA1 (SQUA/AP1) -like genes (GSQUAs) is reported elsewhere [48]. To summarize, GSQUA1 and GSQUA3 group together with AP1 and CAULIFLOWER (CAL) of Arabidopsis [49,50], while GSQUA2, GSQUA4, GSQUA5 and GSQUA6 are phylogenetically closer to the Arabidopsis FRUITFULL (FUL) gene [51,52].

\section{Expression patterns of Gerbera SEP-like genes}

Of eudicot MADS box genes, $\mathrm{C}$ and $\mathrm{B}$ function genes generally show a narrow expression pattern, which directly reflects their function in carpel, stamen, and petal development, respectively $[27,53,54]$. On the other hand, the Arabidopsis SEP genes, necessary for several processes in floral development, are widely expressed in flowers [55-57]. In order to gain potential insight into their function and interaction range, the expression patterns for Gerbera MADS box genes were studied using RNA gel blots and in situ hybridization.

The expression patterns for GSQUA1, GDEF1, GDEF2, GGLO1, GAGA1, GAGA2, GRCD1, GRCD2, GSQUA2, GSQUA3, and GSQUA5 were reported previously $[39,41,42,48]$ (See Additional file 2, Table S1).

According to RNA gel blots probed with a gene specific probe, strongest expression of GRCD3 was seen in inflorescence, petals and ovary. GRCD3 was also expressed in carpel and receptacle and weak expression was detectable in stamens, pappus bristles and bracts (Figure 1a). GRCD3 expression was found to be strongest during the earlier stages (1-7; see [58]) of Gerbera ray flower petal development (Additional file 3, Figure S2), and only very

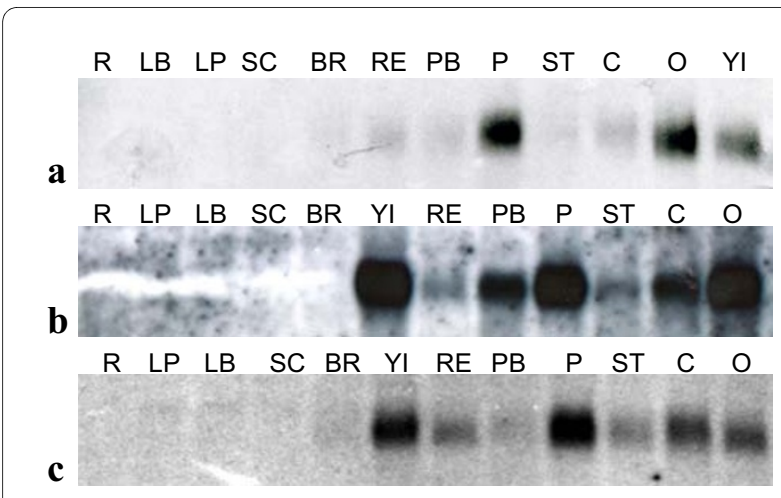

Figure 1 Expression patterns of (a) GRCD3, (b) GRCD4, and (c) GRCD5 in different Gerbera organs by RNA gel blots. R, roots; LP, leaf petiole; $L B$, leaf blade; $S C$, scape; $B R$, bracts; $R E$, receptacle; $\mathrm{PB}$, pappus bristles; $\mathrm{P}$, petals; $\mathrm{ST}$, stamens; $\mathrm{C}$, carpel; $\mathrm{O}$, ovary; $\mathrm{YI}$, young inflorescence (6-16 $\mathbf{~ m m}$ in diameter). All GRCDs studied here display similar, widespread inflorescence abundant expression pattern weak expression was seen at the last stages assayed, 1011.

GRCD4 expression was found to be strongest in young Gerbera inflorescences (6-16 $\mathrm{mm}$ in diameter) and in petals and ovaries, while carpels and pappus bristles gave a slightly weaker signal for expression in the RNA gel blot. Weak, but detectable signal was observed in the receptacle and stamens. No signal was detected in the inflorescence-derived green organs (scape and bracts), or vegetative organs, which included leaf petioles, leaf blades and roots (Figure 1b). GRCD4 was expressed throughout ray flower petal development, clearly fading toward later developmental stages (Additional file 3, Figure S2).

The expression of GRCD5 was inflorescence-abundant according to an RNA gel blot probed with a gene specific probe. GRCD5 was expressed in all floral whorls, with the strongest expression detected in young inflorescence (6$16 \mathrm{~mm}$ ) and petal samples. Slightly weaker expression was detected in receptacle, stamens, carpel and ovary. In bracts and the outmost floral whorl of Gerbera, pappus bristles, GRCD5 was expressed at a very low level (Figure 1c). Interestingly, the expression of GRCD5 differs from the expression of GRCD3 and GRCD4 during ray flower petal development. Both GRCD3 and GRCD4 were expressed at earlier stages of development, whereas GRCD5 showed remarkable upregulation in the late stages, when the Gerbera inflorescence starts to open (Additional file 3, Figure S2). Our microarray study supported this observation [59].

GRCD3 was expressed in several floral organs as shown by in situ hybridization. Strong expression was visible in ovule, carpel and petals. Slightly weaker expression was discovered in stamens and pappus bristles (Figure 2a). In situ, both GRCD4 and GRCD5 were widely expressed in all floral whorls, confirming the results shown by RNA gel blots (Figure 2b and 2c). Overall, the expression patterns for both GRCD4 and GRCD5 were remarkably similar.

\section{Gerbera SEP-like proteins are involved in broad pairwise interactions}

Pairwise interaction capacity between Gerbera MADS domain proteins was tested for all combinations of the fourteen proteins using the yeast two-hybrid assay. The Gerbera proteins were translationally fused separately to both the binding domain and the activation domain, and were combined in both directions.

As summarized in Figure 3, the most broadly interacting proteins in pairwise assays are those phylogenetically grouping with the E function, or SEP-like, MADS domain factors. GRCD4 and GRCD5 each interacted with eight of the fourteen proteins in the interaction screen, including the only two self-interactions (homodimer formation) 


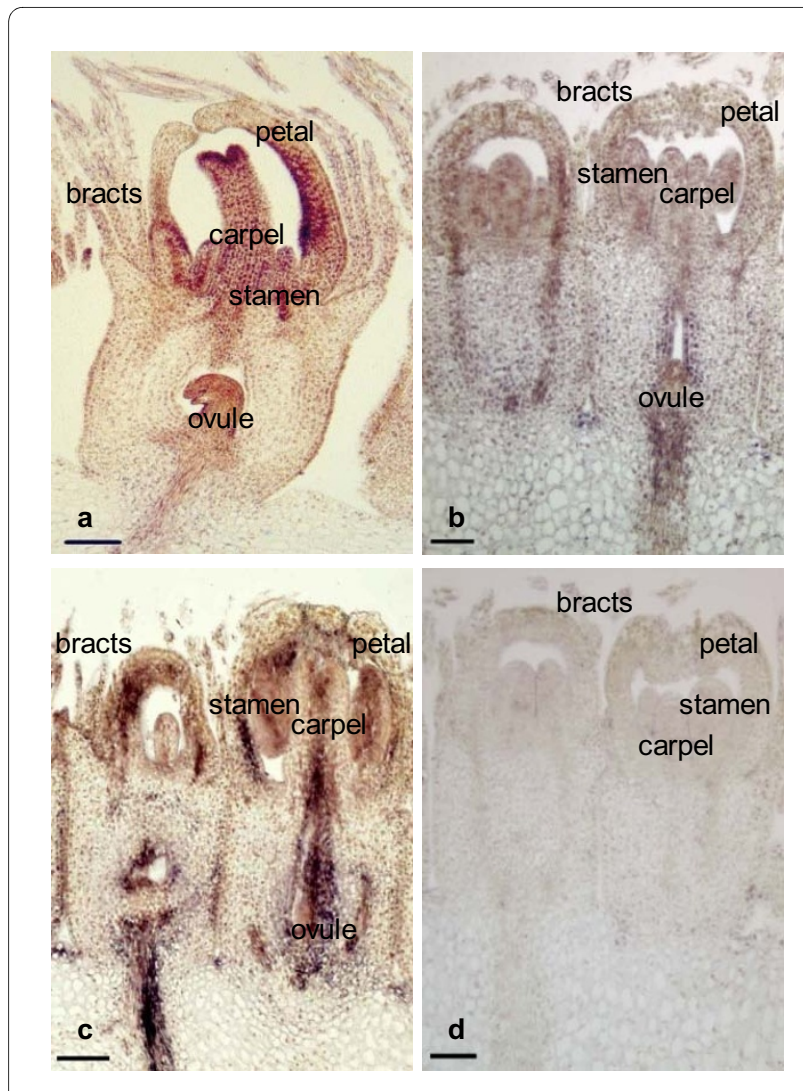

Figure 2 Expression of Gerbera GRCD3, GRCD4, and GRCD5 at in situ level. (a) GRCD3 anti-sense $13 \mathrm{~mm}$, (b) GRCD4 anti-sense $14 \mathrm{~mm}$, (c) GRCD5 anti-sense $12.7 \mathrm{~mm}$, (d) GGLO1 sense $14 \mathrm{~mm}$ as negative control. Size of the inflorescence diameter given in $\mathrm{mm}$.

observed among our assays. These factors interacted with all other Gerbera MADS domain proteins except those from the B-clade (i.e., GGLO1, GDEF1 and GDEF2), the SEP-like protein GRCD1, and the FUL-like protein

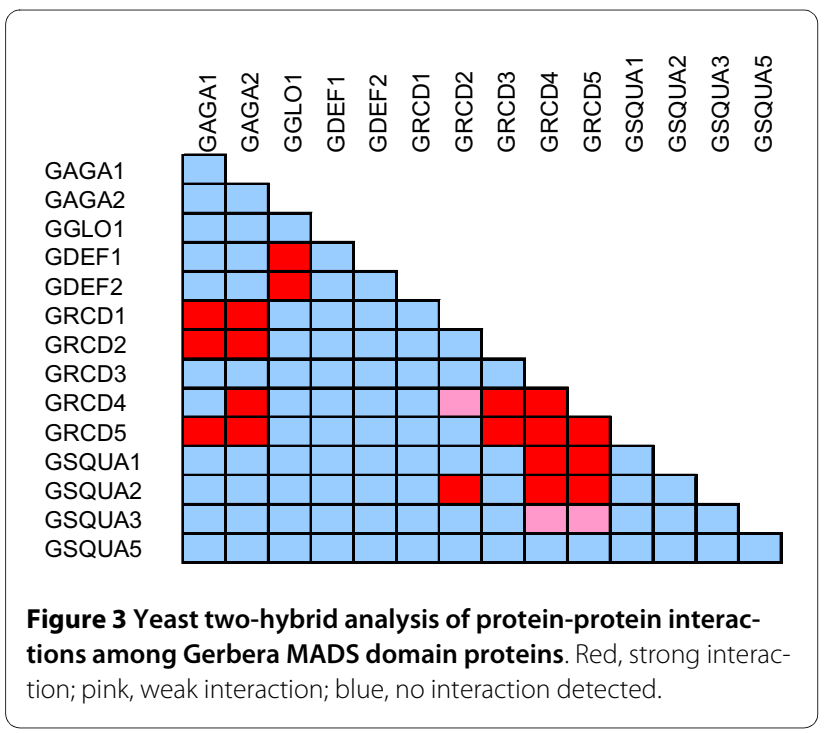

GSQUA5. In addition, GRCD4 did not interact with GAGA2, and GRCD5 not with GRCD2. Both GRCD4 and GRCD5 were assayed as truncated proteins due to a strong autoactivation reaction.

GRCD1 and GRCD2 have been functionally characterized previously, and they take part in whorl-specific homeotic functions in stamens and carpels, respectively. Furthermore, GRCD2 is required for meristem identity and determinacy [41,42]. Compared to the Arabidopsis SEP proteins, these two Gerbera proteins showed a limited interaction capacity in our assays. GRCD1 and GRCD2 both interacted with the C-function proteins GAGA1 and GAGA2, as we have previously observed. In addition, GRCD1 had no other pairwise partners, while GRCD2 interacted with GRCD4 and GSQUA2. GRCD3 has perhaps the most limited interaction pattern of the Eclass family, interacting pairwise only with GRCD4 and GRCD5. GRCD3 is placed in the outermost branch together with AGL6 of Arabidopsis [60].

The floral homeotic $\mathrm{C}$ function genes GAGA1 and GAGA2 show similar expression patterns and similar transgenic phenotypes [39]. Indeed, GAGA1 and GAGA2 behaved similarly as well in protein interaction assays, forming dimers with the SEP-like Gerbera proteins GRCD1, GRCD2 and GRCD5. GAGA2 also formed a dimer with GRCD4.

The homeotic B function is represented in Gerbera by the genes GGLO1 and GDEF2. These genes show strong whorl-specific expression patterns typical of B function MADS box genes, as well as characteristic homeotic changes in transgenic Gerbera lines [39,61]. Gerbera also harbors a TM6-like gene, GDEF1, which is closely related to $G D E F 2$, but based on its expression pattern and transgenic analyses, apparently does not contribute to the classical B function. Recent results indicate that TM6-like genes take part in the control of stamen development $[62,63]$, also in Gerbera [61]. The GGLO1 and GDEF2 proteins show strong interaction as expected for a pair responsible for the $\mathrm{B}$ function. Interestingly, GDEF1 also interacts with GGLO1 in yeast. In a pairwise interaction assay, these three proteins do not interact with any other Gerbera MADS domain proteins.

Homeotic A function genes have not been described in Gerbera - in fact MADS box genes responsible for sepal and petal identity as per the $\mathrm{ABC}$ model have not been identified in plants other than Arabidopsis, (reviewed in $[40,64])$. Nevertheless, Gerbera contains several genes similar to the Arabidopsis A function MADS box gene $A P 1$ and its paralogs $C A L$ and $F U L$, or its ortholog in snapdragon, SQUA [49-52,65]. Altogether six SQUA-like genes have been identified in Gerbera [39,59,48]. Full length cDNAs for GSQUA1, GSQUA2, GSQUA3 and GSQUA5 were included in this study. The corresponding proteins did not interact among themselves in any pair- 
wise combination. All but GSQUA5 interacted with the SEP-like protein GRCD5. Interestingly, GSQUA2 also interacted with GRCD2 in the pairwise assay. GRCD2 represents another SEP-like gene in Gerbera, with pleiotropic functions in carpel identity, floral meristem identity and inflorescence determinacy [42].

\section{Higher order complexes between Gerbera MADS domain proteins}

Plant MADS domain proteins are known to bind DNA only after dimerization $[16,19]$. However, their function in the regulation of flower development has been implied to involve formation of higher order protein complexes, possibly tetramers as depicted in the floral quartet model $[4,7]$. We tested if higher order complex formation could be promoted between Gerbera MADS domain proteins that did not show pairwise interactions. This was done by introducing a third protein into the system in the yeast three-hybrid assay. For example, SEP-like proteins have previously been reported to act as "glue proteins" by facilitating interactions between partners that remain inactive in yeast two-hybrid studies $[3,46]$. In the yeast threehybrid assay, care was taken to avoid a positive signal due to a pairwise interaction. However, the assay became uninformative for this reason only in situations where the three proteins all interacted pairwise. Our survey was not exhaustive, but out of 531 possible (informative) combinations, 313 that were considered to be of high relevance were tested. In a few cases, we found out that an activation function emerged when two MADS domain proteins interacted. This type of autoactivation (see below) was unexpected but is interesting. In practice, however, it resulted in some uninformative three-hybrid assays.

The Gerbera B function proteins GGLO1 and GDEF2 formed a closed interaction pair showing pairwise association only with each other. Still, the GGLO1/GDEF2 heterodimer is involved in different developmental processes, leading to petal development in whorl 2 and stamen development in whorl 3. We tested formation of higher order complexes by fusing GDEF2 (or GDEF1) to the binding domain in PDEST32, then providing GGLO1 as an unfused protein in pARC351 to the yeast cells, and assaying which Gerbera MADS domain proteins (those not interacting with GDEF1 or GDEF2), fused with the activation domain of pDEST22, gave a positive signal when GGLO1 was already complexed with either GDEF1 or GDEF2. In these assays, both $\mathrm{C}$-function proteins GAGA1 and GAGA2 interacted with the GGLO1/GDEF1 and GGLO1/GDEF2 dimers. All Gerbera SEP-like proteins except GRCD1 showed interaction with GGLO1/ GDEF1 and GGLO1/GDEF2 dimers as well, although none of them interacted with the B-class proteins alone. Similarly, all GSQUA proteins interacted with the dimer GGLO1/GDEF2 - but none of them with the dimer GGLO1/GDEF1 (Figure 4).
These results indicate that GGLO1, GDEF1 and GDEF2 are activated not only for their (putative) transcriptional function by heterodimer formation, but also for their capacity to recruit additional proteins to form a transcriptional complex. We also observed that all three B clade proteins were, individually, captured into higher order complexes when expressed together with various combinations of GRCD and GSQUA proteins. Further, combinations of a GAGA protein and a GRCD protein typically recruited the GDEF proteins, but not GGLO1, in higher order complexes (Figure 4).

The two C-clade genes GAGA1 and GAGA2 have been considered similar in their function based on expression patterns and transgenic analysis. Also the pairwise interaction patterns of GAGA1 and GAGA2 are very similar. The test for higher order complexes with yeast threehybrid assay showed differences, however. Generally GAGA1 was more active in threeway complexes than GAGA2, and in addition they showed complementary specificities in some cases. GAGA2 was active together with GRCD1 and GSQUA proteins while GAGA1 was not, and GAGA1 was active with several other GRCD/ GSQUA combinations where GAGA2 was not active.

\section{Emerging transcriptional activation by complex formation} Interestingly, when the dimers GGLO1/GDEF1 and GGLO1/GDEF2 were combined with an empty activation domain containing vector pDEST22, or completely without an activation domain carrying plasmid, yeast growth resulted on plates selecting for weaker interactions (Additional file 4, Table S2). This was unexpected, since transcriptional activation of MADS domain protein complexes are thought to be brought on by specific members of the complex, typically proteins of the SEP family [66]. In order to avoid false results from the yeast three-hybrid assay, we reassayed all sets of binding domain/unfused proteins where yeast growth was observed, irrespective of which MADS domain protein was fused to the activation domain (Additional file 4, Table S2). In addition to growth under weak selection for the GGLO1/GDEF1 and GGLO1/GDEF2 dimers mentioned above, we observed that the combinations GAGA1/GRCD2, GAGA2/GRCD2 and GSQUA2/GRCD2 (without added activation domain) resulted in prominent growth of yeast under strong selection. All of these proteins interacted pairwise in yeast two-hybrid assay, but none of them alone had autoactivation capacity. While obstructing a number of yeast three-hybrid results (see Additional file 4, Table S2), this phenomenon is interesting in itself and shows that transcriptional activation may be a combined function of two interacting proteins.

\section{Discussion}

The major aim of this work was to investigate the interaction capacity of Gerbera MADS domain proteins using 

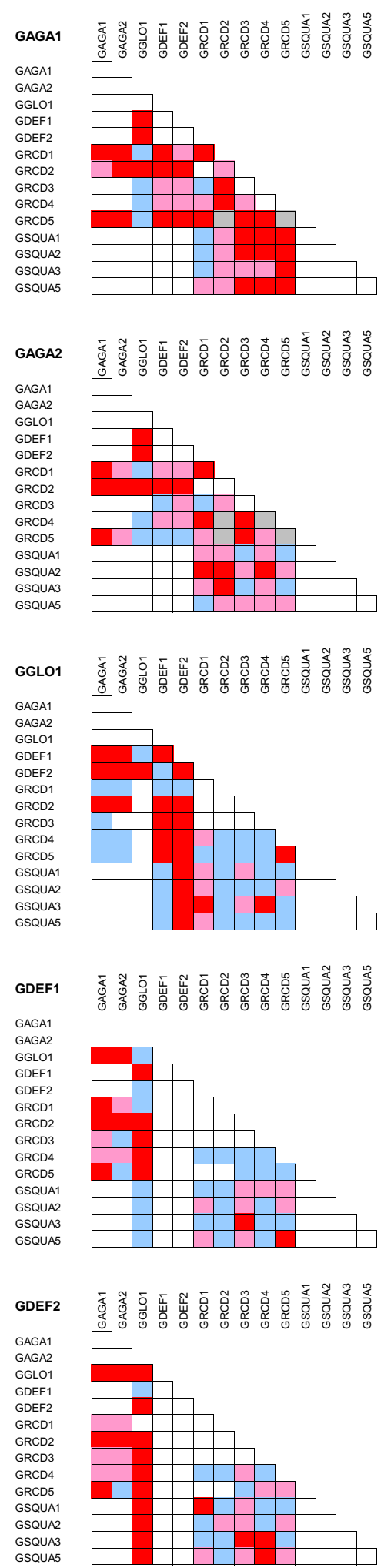
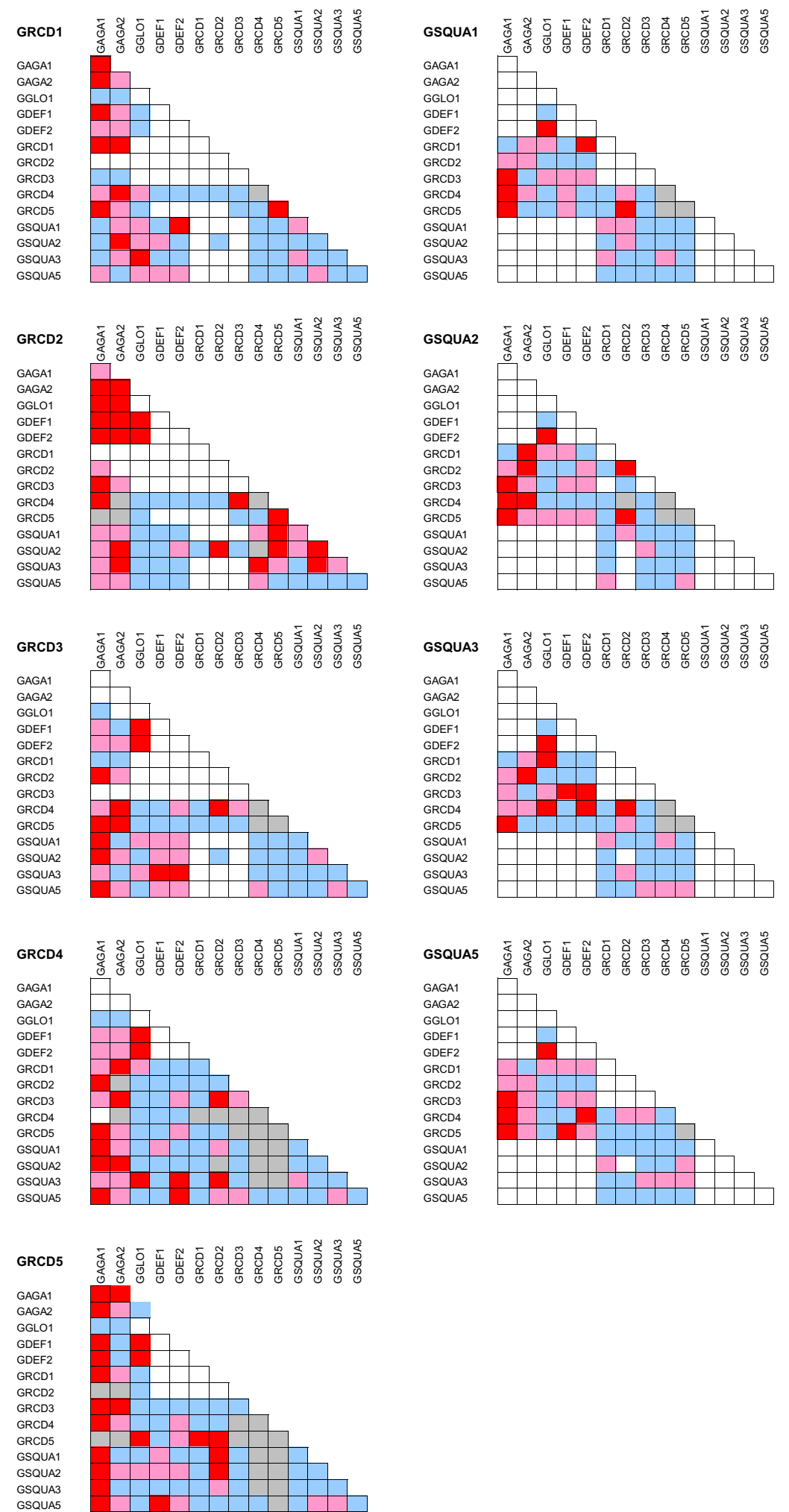

Figure 4 Yeast three-hybrid analysis of ternary protein complex formation among Gerbera MADS domain proteins. Red, strong interaction; pink, weak interaction; blue, no interaction; grey, interaction test uninformative; white, not tested. 
the yeast two-hybrid and three-hybrid assays. In addition, we report expression patterns for three Gerbera SEP-like MADS box genes, GRCD3, GRCD4, and GRCD5. Expression of other Gerbera MADS-box genes has been published previously (see Additional file 2, Table S1). Although protein interaction in yeast is not always conclusive for interaction in planta, our analysis uncovered intriguing information that can be used to compare and classify Gerbera MADS domain proteins with reference to those of Arabidopsis and Petunia, as well as to speculate, in the light of our reverse genetics studies, about the regulatory roles of MADS box genes during differential development of flowers and floral organs in Asteraceae.

\section{GRCD4 and GRCD5 encode general E function proteins in Gerbera}

E function proteins have been reported to be particularly active in forming heterodimers in yeast two-hybrid experiments in several plant species $[8,18,23,44,67]$. For example, the Arabidopsis proteins SEP1 and SEP3 form nodes in the pairwise interaction map and are thought to be responsible for transcriptional activation of a number of different higher order complexes of MADS domain proteins [67]. At least one of the redundant SEP proteins is required for floral organ identity determination where specificity is determined through the combination of $\mathrm{A}, \mathrm{B}$ and $C$ function proteins [3]. In Gerbera, similarly to the (redundantly encoded) E function in Arabidopsis, proteins from the SEP clade are needed to accomplish correct organ identity determination, and specifically, to mediate the activity of the Gerbera $\mathrm{C}$ function encoded by the genes GAGA1 and GAGA2 [41,42]. As the SEP-like Gerbera gene GRCD1 is needed for stamen (more precisely, staminode) identity determination, and GRCD2 for carpel identity determination, we have concluded that the homeotic $\mathrm{E}$ function has evolved into a whorl-specific set of subfunctionalized gene paralogs [41,42].

Mapping of Gerbera MADS domain protein interactions sheds new light on these conclusions and to the roles of Gerbera SEP-like genes. While the Gerbera GRCD1 and GRCD2 proteins have evolved to carry out whorl specific functions similar to the E function in Arabidopsis, they have concomitantly lost their general focal position in the interaction map - they interact with a very limited number of other MADS domain proteins, in fact nearly exclusively with the $\mathrm{C}$ function GAGA proteins, for which they were described as necessary companions based on transgenic phenotypes [41,42].

Instead, GRCD4 and GRCD5 display a hub-like position in the Gerbera interaction map similar to SEP1 and SEP3 in Arabidopsis (Figure 5). Further, like SEP1 and SEP3, GRCD4 and GRCD5 harbor transcriptional activation domains based on their autoactivation capacity in yeast, making them the most likely Gerbera candidates

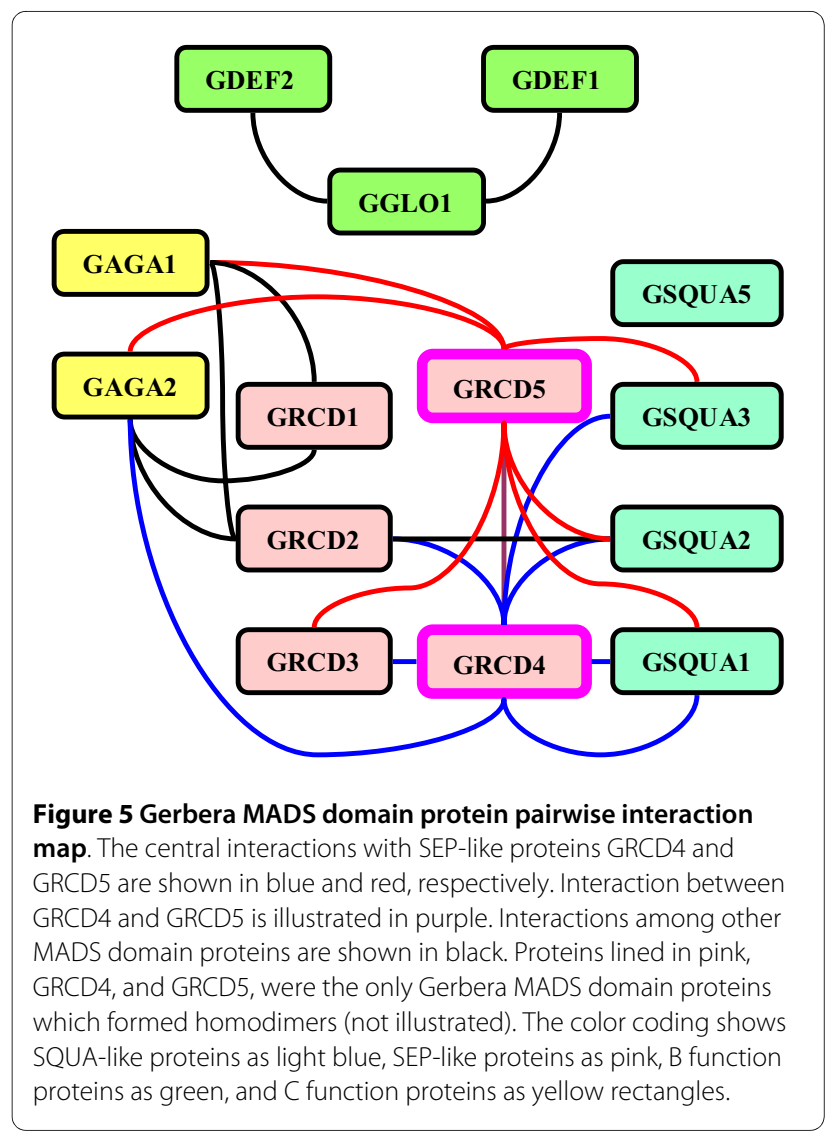

for the necessary and general, whorl non-specific floral $\mathrm{E}$ function proteins. This is supported by their expression analysis, which shows that GRCD4 and GRCD5 are expressed in all floral whorls. Although their interaction capacity is partly complementary (Figure 3), lack of prominent transgenic phenotypes for either of them downregulated alone (data not shown) suggests redundancy. Specifically, this interpretation predicts that a double transformant (with both GRCD4 and GRCD5 downregulated) should show a strong (negative) floral phenotype.

\section{GRCD1 and GRCD2 provide specialized functions in Gerbera}

While a general $\mathrm{E}$ function is encoded by GRCD4 and GRCD5 in Gerbera, our interaction data reinforces the conclusion $[41,42]$ that $G R C D 1$ and $G R C D 2$ are specific and necessary activators of the Gerbera $C$ function, encoded by the genes GAGA1 and GAGA2. However, the whorl specificity of GRCD1 and GRCD2 function remains incompletely characterized. Both genes are expressed in whorls three and four, and both proteins interact with GAGA1 and GAGA2. Nevertheless, GRCD2 cannot replace GRCD1 in whorl three, and GRCD1 cannot replace GRCD2 in whorl four $[41,42]$. Furthermore, transgenic Gerbera plants in which GRCD1 is downregu- 
lated carry petal-like organs in whorl three of ray flowers (in place of the staminodia in non-transgenic plants), but the stamens of the central disc flowers are nearly normal and male fertile. As we have concluded previously, redundant action by other MADS domain proteins may be taking over the function of GRCD1 in disc flowers [41]. Unless a very low level of expression for GRCD1 is sufficient for normal stamen development in disc flowers, we have yet to determine a disc-flower whorl-three-specific GRCD1-like $\mathrm{C}$ function activator in Gerbera.

\section{Differential interactions with the $B$ clade proteins}

Both the developmental and biochemical aspects of $B$ function genes have been found to be highly conserved (reviewed in [68]). B function proteins are necessary for petal and stamen development [6]. As Gerbera flower types differ in size and development of exactly these two organs, the behavior of B function proteins is of particular interest to us. We have earlier concluded that arrest of stamen development in marginal flowers is not due to differential expression of GGLO1 or GDEF2 in developing flower primordia; both genes are expressed strongly at early stages of all flower types [39].

Yeast two-hybrid results indicated that both GDEF1 and GDEF2 proteins readily form heterodimers with GGLO1. Remarkably, the B function dimers were discovered to have an intrinsic activation capacity, not present in the proteins when expressed alone in yeast (Additional file 4, Table S2). It is well known that dimerization of MADS domain proteins is necessary for their capacity to bind their target sequences (CArG boxes) in DNA [16], but it has apparently gone unnoticed that dimerization may also render them functional in transcriptional activation, at least in yeast. Other proteins are expected to enhance activation by bringing in more activation capacity; however, even without external activation, the B protein dimer is active.

Yeast three-hybrid results further indicate that GGLO1, GDEF1 and GDEF2 are also activated by heterodimer formation for the capacity to recruit additional proteins in higher order complexes. Both GLO1/GDEF1 and GGLO1/GDEF2 heterodimers interact strongly with the Gerbera C function proteins GAGA1 and GAGA2. Similarly, all GSQUA proteins interact with the B function dimer GGLO1/GDEF2, but none of them with the GGLO1/GDEF1 dimer. The latter is the clearest difference we observed regarding the two Gerbera DEFICIENS-like proteins, and it demonstrates that GDEF1 and GDEF2 are not simply redundant. Instead of the classical B-function proposed for GDEF2, expression pattern and transgenic phenotypes for the TM6-like GDEF1 suggest a role in stamen development [61].

Although none of the Gerbera SEP-like proteins (GRCDs) interact pairwise with the B-clade proteins, all of them - except GRCD1 - show strong interaction with GGLO1/GDEF1 and GGLO1/GDEF2 complexes. This may speak for a very specific role for GRCD1 as a whorland flower-type specific $\mathrm{C}$ function partner. The observation relates to the findings of Ito et al. [69] regarding an early, traditional homeotic role of $A G$ in flower organ development, and a late function in anther development. The latter requires postulation of a yet-undescribed activator of $A G$ in Arabidopsis [69], providing yet another example where the $\mathrm{C}$ function is modulated in a certain developmental context.

\section{Single Gerbera B clade proteins participate in higher order protein complexes}

Gerbera B function proteins also participate in trimerous complexes as single proteins. A recent study with tomato proteins showed similar results [45]. Although GDEF2 and GGLO1 are traditionally thought to form an obligatory heterodimer to conduct their joint function, and show dramatically increased interaction capacity when expressed together in yeast three-hybrid, they also show individual interactions with pairs of GAGA and GRCD proteins. The $\mathrm{B}$ function proteins alone are also capable of participating in trimerous complexes where none of the involved proteins interact pairwise. GGLO1 complexes with GRCD1 and GSQUA3, or with GRCD4 and GSQUA3, as well as with GRCD5 and GSQUA2. GDEF2 complexes with GSQUA1 or GSQUA5 when GRCD1 is present, and weakly with GSQUA2 or GSQUA5 when GRCD5 is present. It is not clear what roles, if any, lone B function proteins may have in floral development.

\section{The pleiotropic GRCD2 protein has hidden activation capacity}

GRCD2 has an extended role in flower development and controls carpel identity, floral meristem identity and inflorescence determinacy [42]. Down regulation of $G R C D 2$ in transgenic plants affects on all these processes, but ectopic expression of GRCD2 does not lead to observable phenotypes, indicating that this protein's activity is dependent on additional factors. We have previously observed (and verify here) protein-protein interactions between GRCD2 and both of the Gerbera Cfunction GAGA proteins, which is in concordance with both the homeotic and floral meristem identity role of GRCD2. To our surprise, GRCD2/GAGA1 and GRCD2/ GAGA2 dimers showed strong capacity for transcriptional activation, not present for any of the proteins alone. Another protein pair which gains marked transcriptional activation upon dimerization is GRCD2/ GSQUA2. G SQUA2 has, unlike any of the other MADS box genes of Gerbera, a strong flowering inducing capacity when expressed ectopically [48]. Both GRCD2 and GSQUA2 are co-expressed in the young undifferentiated 
inflorescences at the early stages of development, and later the expression patterns of these genes overlap in several floral organs $[42,48]$.

\section{A multitude of higher order protein complexes may be critical for Gerbera stamen development}

Based on the protein interactions presented in this study, we propose hypothetical higher order protein complexes involved in Gerbera stamen identity determination. For determination of stamen identity, a B function protein pair (GDEF2/GGLO1) is required, along with a $\mathrm{C}$ function protein (GAGA1 or GAGA2). Due to the expression pattern of $G D E F 1$, and its links to stamen development [61], the GDEF1/GGLO1 dimer may also be involved. The broad interaction capacity and transcriptional activation properties of GRCD4 and GRCD5 suggest that they, or one of them, are needed for development of all floral organs by bringing together higher order protein complexes and activating them. In this scenario, an obvious deviation from the quartet model is that the number of MADS domain proteins required for stamen development exceeds four.

GRCD1 is needed for stamen development in marginal flowers, and in pairwise assays both Gerbera $C$ function proteins interact with GRCD1. We postulate that even if GRCD1 does not interact directly with the B function protein pair (Figure 4), one possibility is that it would participate in a higher order protein complex by first forming a protein dimer with a GAGA protein. Alternatively, the weaker interaction capacity of GRCD1, compared to other GRCD proteins, could indicate a compromised function, easily competed out by other components necessary for stamen development and eventually leading to release of the developmental arrest in central flowers. Data from microarray experiments show that GRCD1 is in fact upregulated in marginal flowers compared to disc flowers [43].

In vitro data confirming a specific role for MADS domain protein tetramers has recently emerged [70,71], but in planta data is still lacking. Combined analysis of interaction between Gerbera MADS domain proteins indicate that the actual higher order protein transcriptional complexes could be larger than proposed by the quartet model, or (see also [72]) that higher order complex formation in quartets could be transient, with different proteins participating in an alternating manner. Relatively broad expression patterns, especially of GRCD1-5 [[41,42] and this paper] and GSQUA2-5 [48], summarized in Additional file 5, Table S3, provide opportunities for both types of increased complexity.

\section{Conclusions}

Our study shows that Gerbera MADS domain proteins are capable of forming a multitude of higher order com- plexes in yeast assays. Gerbera MADS domain protein behavior in higher order complexes displays both characteristics that are common to all higher eudicots, but also specialized features, some of which may be specific to Asteraceae and its complex inflorescence structure. For example, in Gerbera the $\mathrm{E}$ function is split between the highly specialized GRCD1 and GRCD2 factors, which are active in stamens and carpels, respectively [41,42], and a more general activation capacity provided by GRCD 4 and GRCD5. In other model species, such division of labor among $\mathrm{E}$ function proteins has not been observed to this extent. However, petunia $\mathrm{E}$ class proteins also differ in their higher order complex formation capacity, and single mutant analysis shows only minor phenotypic changes $[73,74,62]$. In contrast to what has been observed for B function proteins in general, Gerbera B function factors (GGLO1, GDEF2 and GDEF1) can participate in higher order complexes as single proteins, with the requirement for heterodimerization bypassed. Based on the data presented here, we speculate that the differential development of Gerbera flower types, especially that of the stamen whorl, requires more complexity than development of flowers in simple inflorescences that bear uniform flowers.

\section{Methods}

\section{Gerbera MADS box genes used in interaction studies}

Isolation of Gerbera MADS box genes GGLO1, GDEF1, GDEF2, GAGA1, GAGA2 and GSQUA1 has been reported previously [39]. Isolation of the Gerbera $A P 1 /$ SQUA-like genes (GSQUAs) is described elsewhere [48]. $G R C D 3$ was cloned from a petal library using a degenerate oligonucleotide [75] encoding an eight amino acid sequence of Arabidopsis AGAMOUS. GRCD4 and $G R C D 5$ were identified as full-length cDNA clones from the Gerbera EST collection [59]. The recently identified paralogue of GDEF2, GDEF3 [61], was not included in this study. Summary of Gerbera MADS box genes used in this study is shown in Additional file 2, Table S1.

\section{Phylogenetic analysis}

Parsimony analyses were performed on a nucleotide sequence matrix, modified from [47] to include all Gerbera GRCD genes. The modified data set was first translated to aid alignment, and then precisely back-translated to yield the original DNA sequences. The data set was analyzed using the TNT application [76] with the "new technology" option in a driven search using sectorial searches, tree-drifting and tree-fusing [77]. Analyses were run until a stabilized consensus had occurred twice using equal character weights and tree bisection-reconnection (TBR) branch swapping. Additional TBR branch swapping was performed on trees resulting from the initial search to find additional equally parsimonious trees. 
Bootstrap support for internal branches was also estimated using TNT. The majority rule consensus tree is shown collapsed for all branches with less than or equal to $50 \%$ bootstrap support. Two hundred and fifty replicates were conducted, each performing TBR branch swapping with 10 random entry orders saving one tree per replicate. Absolute support values are reported.

\section{Expression analysis of GRCD3, GRCD4 and GRCD5}

Total RNA from different plant organs and from different developmental stages of petals (stages 1-11, according to [58]) was isolated using Trizol reagent (Invitrogen, cat. no. 11596-018). Equal amounts $(10 \mu \mathrm{g})$ of RNA were run in a $0.8 \%$ agarose gel as described in [58]. The rRNA bands were visualized by $\mathrm{EtBr}$ staining to record even loading of the gel. The RNA was blotted on a membrane (Hybond-N, Amersham Biosciences) and hybridized (UltraHyb hybridization buffer, Ambion) with a genespecific probes $(213,245$ and $314 \mathrm{bp})$ designed from the 3 ' ends of GRCD3, GRCD4 and GRCD5 cDNA molecules, respectively. Probes were labeled with [32P] dCTP and hybridized at $+42^{\circ} \mathrm{C} 16 \mathrm{~h}$. The membranes were washed with $1 \times \mathrm{SSC}, 0.1 \% \mathrm{SDS}$ at $+42^{\circ} \mathrm{C}$ for 20 minutes. Subsequent washes were performed at $+65^{\circ} \mathrm{C}$ for 15 minutes, 1 2 times.

In situ hybridization analysis was performed as described in [78,79]. GRCD3, GRCD4 and GRCD5 genespecific sense and antisense probes (213, 245 and $314 \mathrm{bp})$ were prepared and quantitated using DIG RNA labeling kit (Boehringer Mannheim) according to the manufacturer's instructions. $10 \mu \mathrm{m}$ thick paraffin sections were mounted in $50 \%$ glycerol after hybridization.

\section{Construction of Gateway entry plasmids}

All full length Gerbera MADS box genes were introduced as cDNAs into the Gateway system using PCR (PCR Cloning System with Gateway Technology with pDONR221, Invitrogen). Primers flanking the first methionine of the gene and the stop codon were designed according to Invitrogen's instructions. Two nucleotides were added between the attB1 sequence and the start codon. Primers and Gateway sequences are shown in Additional file 6, Table S4.

The PCR products were purified and recombined with pDONR221 (Invitrogen) plasmid to create Gateway entry clones according to the manufacturer's instructions. All entry clones were sequenced to eliminate possible PCR artifacts.

\section{Yeast assays}

Entry plasmids carrying Gerbera MADS box genes were recombined with the activation and binding domain containing plasmids pDEST22 and pDEST32 (Invitrogen) and transformed to yeast (Saccharomyces cerevisiae) strains PJ69-4A and PJ69-4 $\alpha$ [80]. All plasmids were introduced in both yeast mating types. The pDEST32 clones containing $\mathrm{N}$-terminal binding domain fusions were tested for autoactivation by plating them on the yeast medium SD $(0.67 \%$ yeast nitrogen base without amino acids, $2 \%$ glucose, and appropriate amino acids) lacking adenine (SD -Ade), or histidine (SD -His) and supplemented with 1, 5 or $10 \mathrm{mM} 3$-amino-1,2,4-triazole (3-AT) (Sigma A8056). Autoactivation was observed for GRCD4 and GRCD5, and C terminal deletions were introduced to these constructs [81]. Deletions (Additional file 7, Figure S3) were designed so that the predicted alpha helical structure that starts within the conserved $\mathrm{K}$ domain and extends towards the $\mathrm{C}$ terminus of the protein was retained [82]. After deletions, autoactivation of the truncated constructs were retested both in absence and presence of an empty activation domain containing vector and were found negative. To obtain yeast double transformants, the $\mathrm{A}$ and $\alpha$ types of yeast strains were mated by pipetting them on top of each other on rich medium (SD Glu Complete). Yeast double transformants were plated on selection plates SD -Leu -Trp -Ade and SD -Leu -Trp -His + 1,5 or $10 \mathrm{mM} 3$-AT. The plates were incubated at $+22^{\circ} \mathrm{C}$ for 5 days. We scored a positive signal for interaction capacity if either of the directions resulted in growth of yeast on the selection medium (Additional file 8, Figure S4). Reciprocal tests gave the same result in all cases, except that the truncated GRCD4 fused to the binding domain gave consistently poor growth with other Gerbera MADS domain proteins except GRCD4 (homodimer formation) and GRCD5 (Additional file 9, Table S5).

For yeast three-hybrid assays, the plasmid pARC351 (Gateway compatible pRED-NLSa plasmid derivative, P. Ouwerkerk; Gateway modifications by R. Immink) was used to express the third protein of interest in yeast cells. The previously cloned Gateway entry plasmids were recombined with pARC351 according to Invitrogen's instructions. The purpose of this assay was to see whether two proteins inactive in yeast two-hybrid experiment could interact in the presence of a third protein. 313 combinations of three proteins were tested (Additional file 4, Table S2). The criteria for selecting the combinations was decided based on the $\mathrm{ABC}(\mathrm{DE})$ model and the previous results $[2,6,7,83,73,84,85,45]$ The yeast threehybrid interactions were selected on plates SD -Leu -Trp Ura -Ade and SD -Leu -Trp -Ura -His, with 1, 5 and 10 $\mathrm{mM}$, or 10 and $25 \mathrm{mM} 3-\mathrm{AT}$, respectively. The plates were incubated at $+22^{\circ} \mathrm{C}$ for 7 days.

Some yeast three-hybrid combinations gave positive signals regardless of which protein was fused with the activation domain. For these combinations we run extra controls where the activation domain containing vector pDEST22 was left out or was present empty in the yeast 
cells. In these controls, strong intrinsic autoactivation was discovered for Gerbera MADS domain protein dimers GRCD2/GAGA1, GRCD2/GAGA2, and GRCD2/ GSQUA2, rendering some of the studied ternary protein complexes uninformative (see Additional file 4, Table S2). The limitation applied to protein combinations where GRCD2 was fused to the binding domain containing vector pDEST32, and GAGA1, GAGA2, or GSQUA2 was supplied from pARC351 vector, or vice versa. Gerbera Bclade protein dimers GGLO1/GDEF2 and GGLO1/ GDEF1 selected under milder conditions exhibited similar autoactivation, but ternary complexes containing either Gerbera B-clade protein dimer and activating under stringent selection were scored as true positives.

\section{Additional material}

Additional file 1 Phylogenetic tree. A phylogenetic tree showing the positions of Gerbera SEP-like genes.

Additional file $\mathbf{2}$ Gerbera MADS box genes. Summary of Gerbera MADS box genes used in this study.

Additional file 3 Expression during ray flower development. RNA gel blots showing expression of GRCD3, GRCD4 and GRCD5 during Gerbera ray flower development.

Additional file 4 Original yeast three-hybrid data. Scores and interpretation of all yeast three-hybrid data collected.

Additional file $\mathbf{5}$ Expression of Gerbera MADS box genes. Expression summary of Gerbera MADS box genes in different floral organs. The results are from RNA gel blot and in situ hybridization data.

Additional file 6 Primer sequences. Primer sequences of Gerbera MADS box genes used for Gateway (Invitrogen) conversion.

Additional file 7 Alignment of protein sequences. Alignment of Gerbera GRCD1-5 and Arabidopsis SEP3 protein sequences.

Additional file 8 Yeast three-hybrid analysis. An example of yeast threehybrid analysis of MADS-domain proteins on SD -Leu, -Trp, -Ura, -Ade plate. Additional file 9 Original yeast two-hybrid data. Scores and interpretation of all yeast two-hybrid data collected.

\section{Authors' contributions}

SR participated in the design of the experiment, carried out the expression analyses and the interaction experiments and drafted the manuscript. YPN participated in setting up the Gateway system. VAA performed the phylogenetic analysis, participated in the analysis of the results and helped to draft the manuscript. PE participated in the design of the experiment, analysis of the results and helped to draft the manuscript. THT coordinated the research, participated in the design of the experiment and analysis of the results and helped to draft the manuscript. All authors read and approved the final manuscript.

\section{Acknowledgements}

Both yeast strains PJ69-4A, PJ69-4a and plasmid pARC351 were kind gifts from Dr. Richard Immink of Wageningen Plant Research International, the Netherlands. His unrelentless willingness to share information at various stages of this work is gratefully acknowledged. Permission to use plasmid pRed-NLSa was granted by Professor Pieter Ouwerkerk, University of Leiden, the Netherlands. Professor Hong Ma transmitted the original data matrix used in the phylogenetic analyses of Zahn et al. [47]. Dr. Sari Tähtiharju is thanked for reemphasizing the importance of controls. Eija Takala is thanked for excellent technical assistance. Academy of Finland is acknowledged for funding (Grant no 207410 and the Programme for Centres of Excellence in Research).

\section{Author Details}

${ }^{1}$ Gerbera Laboratory, Department of Applied Biology P.O. Box 27 (Latokartanonkaari 7), FIN - 00014 University of Helsinki, Finland, ${ }^{2}$ Current Address: Biomedicum Helsinki, P.O. Box 63 (Haartmaninkatu 8), FIN-00014 University of Helsinki, Finland and ${ }^{3}$ Department of Biological Sciences, University at Buffalo (SUNY), Buffalo, NY 14260, USA

Received: 27 October 2009 Accepted: 25 June 2010

Published: 25 June 2010

\section{References}

1. Becker A, Theissen G: The major clades of MADS-box genes and their role in the development and evolution of flowering plants. Mol Phylogenet Evol 2003, 29:464-489.

2. Egea-Cortines M, Saedler $\mathrm{H}$, Sommer $\mathrm{H}$ : Ternary complex formation between the MADS-box proteins SQUAMOSA, DEFICIENS and GLOBOSA is involved in the control of floral architecture in Antirrhinum majus. EMBO J 1999, 18:5370-5379.

3. Honma T, Goto K: Complexes of MADS-box proteins are sufficient to convert leaves into floral organs. Nature 2001, 409:525-529.

4. Theissen G: Development of floral organ identity: stories from the MADS house. Curr Opin Plant Biol 2001, 4:75-85.

5. Theissen G, Melzer R: Molecular mechanisms underlying origin and diversification of the angiosperm flower. Ann Bot 2007, 100:603-619.

6. Coen ES, Meyerowitz EM: The war of the whorls: genetic interactions controlling flower development. Nature 1991, 353:31-37.

7. Theissen G, Saedler H: Plant biology. Floral quartets. Nature 2001, 409:469-471.

8. Pelaz S, Gustafson-Brown C, Kohalmi SE, Crosby WL, Yanofsky MF: APETALA1 and SEPALLATA3 interact to promote flower development. Plant J 2001, 26:385-394.

9. Norman C, Runswick M, Pollock R, Treisman R: Isolation and properties of CDNA clones encoding SRF, a transcription factor that binds to the cfos serum response element. Cell 1988, 55:989-1003.

10. Passmore $\mathrm{S}$, Elble $\mathrm{R}$, Tye BK: A protein involved in minichromosome maintenance in yeast binds a transcriptional enhancer conserved in eukaryotes. Genes Dev 1989, 3:921-935.

11. Yanofsky MF, Ma H, Bowman JL, Drews GN, Feldmann KA, Meyerowitz EM: The protein encoded by the Arabidopsis homeotic gene agamous resembles transcription factors. Nature 1990, 346:35-39.

12. Sommer H, Beltran JP, Huijser P, Pape H, Lonnig WE, Saedler H, SchwarzSommer Z: Deficiens, a homeotic gene involved in the control of flower morphogenesis in Antirrhinum majus: the protein shows homology to transcription factors. EMBO J 1990, 9:605-613.

13. Schwarz-Sommer Z, Hue I, Huijser P, Flor PJ, Hansen R, Tetens F, Lonnig WE, Saedler H, Sommer H: Characterization of the Antirrhinum floral homeotic MADS-box gene deficiens: evidence for DNA binding and autoregulation of its persistent expression throughout flower development. EMBO J 1992, 11:251-263.

14. Shore P, Sharrocks AD: The ETS-domain transcription factors Elk-1 and SAP-1 exhibit differential DNA binding specificities. Nucleic Acids Res 1995, 23:4698-4706

15. Cho S, Jang S, Chae S, Kyung MC, Moon YH, An G, Sung KJ: Analysis of the C-terminal region of Arabidopsis thaliana APETALA1 as a transcription activation domain. Plant Mol Biol 1999, 40:419-429.

16. Tröbner W, Ramirez L, Motte P, Hue I, Huijser P, Lonnig WE, Saedler H, Sommer H, Schwarz-Sommer Z: GLOBOSA: a homeotic gene which interacts with DEFICIENS in the control of Antirrhinum floral organogenesis. EMBO J 1992, 11:4693-4704.

17. Classen-Bockhoff R: Pattern analysis in pseudanthia. Plant Syst Evol 1990, 171:57-88.

18. Favaro R, Immink RGH, Ferioli V, Bernasconi B, Byzova M, Angenent GC, Kater M, Colombo L: Ovule-specific MADS-box proteins have conserved protein-protein interactions in monocot and dicot plants. Mol Genet Gen 2002, 268:152-159.

19. Riechmann JL, Krizek BA, Meyerowitz EM: Dimerization specificity of Arabidopsis MADS domain homeotic proteins APETALA1, APETALA3, PISTILLATA, and AGAMOUS. Proc Natl Acad Sci USA 1996, 93:4793-4798.

20. West AG, Causier BE, Davies B, Sharrocks AD: DNA binding and dimerisation determinants of Antirrhinum majus MADS-box transcription factors. Nucleic Acids Res 1998, 26:5277-5287. 
21. Hepworth SR, Valverde F, Ravenscroft D, Mouradov A, Coupland G: Antagonistic regulation of flowering-time gene SOC 1 by CONSTANS and FLC via separate promoter motifs. EMBO J 2002, 21:4327-4337.

22. Davies B, Egea-Cortines M, de Andrade Silva E, Saedler H, Sommer H: Multiple interactions amongst floral homeotic MADS box proteins. EMBO J 1996, 15:4330-4343.

23. Causier B, Cook H, Davies B: An Antirrhinum ternary complex factor specifically interacts with C-function and SEPALLATA-like MADS-box factors. Plant Mol Biol 2003, 52:1051-1062.

24. Masiero S, Imbriano C, Ravasio F, Favaro R, Pelucchi N, Gorla MS, Mantovani R, Colombo L, Kater MM: Ternary complex formation between MADS-box transcription factors and the histone fold protein NF-YB. J Biol Chem 2002, 277:26429-26435.

25. Sridhar W, Surendrarao A, LiU Z: APETALA1 and SEPALLATA3 interact with SEUSS to mediate transcription repression during flower development. Development 2006, 133:3159-3166

26. He C, Sommer H, Grosardt B, Huijser P, Saedler H: PFMAGO, a MAGO NASHI-like factor, interacts with the MADS-domain protein MPF2 from Physalis floridana. Mol Biol Evol 2007, 24:1229-1241.

27. Goto K, Meyerowitz EM: Function and regulation of the Arabidopsis floral homeotic gene PISTILLATA. Genes Dev 1994, 8:1548-1560.

28. Jack T, Fox GL, Meyerowitz EM: Arabidopsis homeotic gene APETALA3 ectopic expression: transcriptional and posttranscriptional regulation determine floral organ identity. Cell 1994, 76:703-716.

29. Zachgo S, Silva Ede A, Motte P, Tröbner W, Saedler H, Schwarz-Sommer Z: Functional analysis of the Antirrhinum floral homeotic DEFICIENS gene in vivo and in vitro by using a temperature-sensitive mutant. Development 1995, 121:2861-2875.

30. Tilly JJ, Allen DW, Jack T: The CArG boxes in the promoter of the Arabidopsis floral organ identity gene APETALA3 mediate diverse regulatory effects. Development 1998, 125:1647-1657.

31. Honma T, Goto K: The Arabidopsis floral homeotic gene PISTILLATA is regulated by discrete cis-elements responsive to induction and maintenance signals. Development 2000, 127:2021-2030.

32. Gómez-Mena C., de Folter S, Costa MM, Angenent GC, Sablowski R: Transcriptional program controlled by the floral homeotic gene AGAMOUS during early organogenesis. Development 2005, 132:429-438.

33. Zhu C, Perry SE: Control of expression and autoregulation of AGL15, a member of the MADS-box family. Plant J 2005, 41:583-594.

34. Lauri A, Xing S, Heidmann I, Saedler H, Zachgo S: The pollen-specific DEFH125 promoter from Antirrhinum is bound in vivo by the MADSbox proteins DEFICIENS and GLOBOSA. Planta 2006, 224:61-71.

35. Gregis V, Sessa A, Colombo L, Kater MM: AGL24, SHORT VEGETATIVE PHASE, and APETALA1 redundantly control AGAMOUS during early stages of flower development in Arabidopsis. Plant Cell 2006, 18:1373-1382.

36. Sundström JF, Nakayama N, Glimelius K, Irish VF: Direct regulation of the floral homeotic APETALA1 gene by APETALA3 and PISTILLATA in Arabidopsis. Plant J 2006, 46:593-600

37. Teeri TH, Kotilainen M, Uimari A, Ruokolainen S, Ng YP, Malm U, Pöllänen E, Broholm S, Laitinen R, Elomaa P, Albert VA: Floral developmental genetics of Gerbera (Asteraceae). Adv Bot Res 2006, 44:323-351.

38. Leppik EE: Homologous and analogous series in the evolution of flower types. Genetika 1969:12-23. [title translated from Russian]

39. Yu DY, Kotilainen M, Pöllänen E, Mehto M, Elomaa P, Helariutta Y, Albert $\mathrm{VA}$, Teeri TH: Organ identity genes and modified patterns of flower development in Gerbera hybrida (Asteraceae). Plant J 1999, 17:51-62.

40. Teeri TH, Uimari A, Kotilainen M, Laitinen R, Help H, Elomaa P, Albert VA: Reproductive meristem fates in Gerbera. J Exp Bot 2006, 57:3445-3455.

41. Kotilainen M, Elomaa P, Uimari A, Albert VA, Yu D, Teeri TH: GRCD1, an AGL2-like MADS box gene, participates in the $C$ function during stamen development in Gerbera hybrida. Plant Cell 2000, 12:1893-1902.

42. Uimari A, Kotilainen M, Elomaa P, Yu D, Albert VA, Teeri TH: Integration of reproductive meristem fates by a SEPALLATA-like MADS-box gene. Proc Natl Acad Sci USA 2004, 101:15817-15822.

43. Laitinen RA, Broholm S, Albert VA, Teeri TH, Elomaa P: Patterns of MADSbox gene expression mark flower-type development in Gerbera hybrida (Asteraceae). BMC Plant Biol 2006, 6:11.

44. Immink RGH, Gadella TWJJ, Ferrario S, Busscher M, Angenent GC: Analysis of MADS box protein-protein interactions in living plant cells. Proc Natl Acad Sci USA 2002, 99:2416-2421.
45. Leseberg $\mathrm{CH}$, Eissler $\mathrm{CL}$, Wang $X$, Johns MA, Duvall MR, Mao L: Interaction study of MADS-domain proteins in tomato. J Exp Bot 2008, 59:2253-2265

46. Immink RGH, Tonaco INA, de Folter S, Shchennikova A, van Dijk ADJ, Busscher-Lange J, Borst JW, Angenent GC: SEPALLATA3: the 'glue' for MADS box transcription factor complex formation. Genome Biol 2009 10:R24.

47. Zahn LM, Kong H, Leebens-Mack JH, Kim S, Soltis PS, Landherr LL, Soltis DE, Depamphilis CW, Ma H: The evolution of the SEPALLATA subfamily of MADS-box genes: a preangiosperm origin with multiple duplications throughout angiosperm history. Genetics 2005, 169:2209-2223.

48. Ruokolainen S, Ng YP, Broholm SK, Albert VA, Elomaa P, Teeri TH: Characterization of SQUAMOSA-like genes in Gerbera hybrida including one involved in reproductive transition. BMC Plant Biol 2010, 10:12

49. Irish VF, Sussex IM: Function of the apetala-1 gene during Arabidopsis floral development. Plant Cell 1990, 2:741-753.

50. Kempin SA, Savidge B, Yanofsky MF: Molecular basis of the cauliflower phenotype in Arabidopsis. Science 1995, 267:522-525.

51. Mandel MA, Yanofsky MF: The Arabidopsis AGL8 MADS box gene is expressed in inflorescence meristems and is negatively regulated by APETALA1. Plant Cell 1995, 7:1763-1771.

52. Gu Q, Ferrandiz C, Yanofsky MF, Martienssen R: The FRUITFULL MADS-box gene mediates cell differentiation during Arabidopsis fruit development. Development 1998, 125:1509-1517.

53. Bowman JL, Drews GN, Meyerowitz EM: Expression of the Arabidopsis floral homeotic gene AGAMOUS is restricted to specific cell types late in flower development. Plant Cell 1991, 3:749-758.

54. Jack T, Brockman LL, Meyerowitz EM: The homeotic gene APETALA3 of Arabidopsis thaliana encodes a MADS box and is expressed in petals and stamens. Cell 1992, 68:683-697.

55. Flanagan $\mathrm{CA}, \mathrm{Ma} \mathrm{H}$ : Spatially and temporally regulated expression of the MADS-box gene AGL2 in wild-type and mutant arabidopsis flowers. Plant Mol Biol 1994, 26:581-595.

56. Savidge B, Rounsley SD, Yanofsky MF: Temporal relationship between the transcription of two Arabidopsis MADS box genes and the floral organ identity genes. Plant Cell 1995, 7:721-733.

57. Ditta G, Pinyopich A, Robles P, Pelaz S, Yanofsky MF: The SEP4 gene of Arabidopsis thaliana functions in floral organ and meristem identity. Curr Biol 2004, 14:1935-1940.

58. Helariutta $Y$, Elomaa $P$, Kotilainen M, Seppänen $P$, Teeri TH: Cloning of CDNA coding for dihydroflavonol-4-reductase (DFR) and characterization of $d$ fr expression in the corollas of Gerbera hybrida var. Regina (Compositae). Plant Mol Biol 1993, 22:183-193.

59. Laitinen RA, Immanen J, Auvinen P, Rudd S, Alatalo E, Paulin L, Ainasoja M, Kotilainen M, Koskela S, Teeri TH, Elomaa P: Analysis of the floral transcriptome uncovers new regulators of organ determination and gene families related to flower organ differentiation in Gerbera hybrida (Asteraceae). Genome Res 2005, 15:475-486.

60. Ma H, Yanofsky MF, Meyerowitz EM: AGL1-AGL6, an Arabidopsis gene family with similarity to floral homeotic and transcription factor genes. Genes Dev 1991, 5:484-495.

61. Broholm SK, Pöllänen E, Ruokolainen S, Tähtiharju S, Kotilainen M, Albert VA, Elomaa P, Teeri TH: Functional characterization of B class MADS-box transcription factors in Gerbera hybrida. J Exp Bot 2009 in press. (doi:10.1093/jxb/erp279)

62. Rijpkema AS, Royaert S, Zethof J, Van Der Weerden G, Gerats T, Vandenbussche M: Analysis of the Petunia TM6 MADS box gene reveals functional divergence within the DEF/AP3 lineage. Plant Cell 2006, 18:1819-1832

63. de Martino G, Pan I, Emmanuel E, Levy A, Irish VF: Functional analyses of two tomato APETALA3 genes demonstrate diversification in their roles in regulating floral development. Plant Cell 2006, 18:1833-1845.

64. Litt A: An evaluation of A-function: Evidence from the APETALA1 and APETALA2 gene lineages. Int J Plant Sci 2007, 168:73-91.

65. Huijser $P$, Klein J, Lonnig WE, Meijer $H$, Saedler $H$, Sommer $H$ Bracteomania, an inflorescence anomaly, is caused by the loss of function of the MADS-box gene squamosa in Antirrhinum majus. EMBO J 1992, 11:1239-1249.

66. Goto K, Kyozuka J, Bowman JL: Turning floral organs into leaves, leaves into floral organs. Curr Opin Genet Dev 2001, 11:449-456. 
67. de Folter S, Immink RGH, Kieffer M, Parenicova L, Henz SR, Weigel D, Busscher M, Kooiker M, Colombo L, Kater MM, Davies B, Angenent GC: Comprehensive interaction map of the Arabidopsis MADS box transcription factors. Plant Cell 2005, 17:1424-1433.

68. Irish VF, Kramer EM: Genetic and molecular analysis of angiosperm flower development. Adv Bot Res 1998:197-230.

69. Ito T, Ng K, Lim T, Yu H, Meyerowitz EM: The Homeotic Protein AGAMOUS Controls Late Stamen Development by Regulating a Jasmonate Biosynthetic Gene in Arabidopsis. Plant Cell 2007, 19:3516-3529.

70. Melzer R, Verelst W, Theissen G: The class E floral homeotic protein SEPALLATA3 is sufficient to loop DNA in 'floral quartet'-like complexes in vitro. Nucleic Acids Res 2009, 37:144-157.

71. Melzer R, Theissen G: Reconstitution of 'floral quartets' in vitro involving class B and class E floral homeotic proteins. Nucleic Acids Res 2009, 37:2723-2736.

72. Immink RGH, Angenent GC: Combinatorial action of Petunia MADS box genes and their protein products. In Petunia. Evolutionary, Developmental and Physiological Genetics 2nd edition. Edited by: Gerats T, Strommer J. New York: Springer Science +Business Media; 2009:225-245.

73. Ferrario S, Immink RGH, Shchennikova A, Busscher Lange J, Angenent GC: The MADS box gene FBP2 is required for SEPALLATA function in petunia. Plant Cell 2003, 15:914-925.

74. Vandenbussche M, Zethof J, Souer E, Koes R, Tornielli GB, Pezzotti M, Ferrario S, Angenent GC, Gerats T: Toward the analysis of the petunia MADS box gene family by reverse and forward transposon insertion mutagenesis approaches: $B, C$ and $D$ floral organ identity functions require SEPALLATA-like MADS box genes in petunia. Plant Cell 2003, 15:2680-2693.

75. Tandre K, Albert VA, Sundas A, Engström P: Conifer homologues to genes that control floral development in angiosperms. Plant Mol Biol 1995 27:69-78.

76. Goloboff PA, Farris JS, Nixon K: TNT: Tree analysis using new technology. 2003 [http://www.zmuc.dk/public/phylogeny/tnt]. Version 1.0

77. Goloboff PA: Analyzing large data sets in reasonable times: solutions for composite optima. Cladistics 1999, 15:415-428.

78. Di Laurenzio L, Wysocka-Diller J, Malamy JE, Pysh L, Helariutta Y, Freshour G, Hahn MG, Feldmann KA, Benfey PN: The SCARECROW Gene Regulates an Asymmetric Cell Division That Is Essential for Generating the Radial Organization of the Arabidopsis Root. Cell 1996, 86:423-433.

79. Mähönen AP, Bonke M, Kauppinen L, Riikonen M, Benfey PN, Helariutta Y: A novel two-component hybrid molecule regulates vascular morphogenesis of the Arabidopsis root. Genes Dev 2000, 14:2938-2943.

80. James P, Halladay J, Craig EA: Genomic Libraries and a Host Strain Designed for Highly Efficient Two-Hybrid Selection in Yeast. Genetics 1996, 144:1425-1436.

81. Moon Y, Kang H, Jung J, Jeon J, Sung S, An G: Determination of the Motif Responsible for Interaction between the Rice APETALA1/AGAMOUSLIKE9 Family Proteins Using a Yeast Two-Hybrid System. Plant Physiol 1999, 120:1193-1204

82. Yang $Y$, Jack T: Defining subdomains of the $K$ domain important for protein-protein interactions of plant MADS proteins. Plant Mol Biol 2004, 55:45-59.

83. Favaro R, Pinyopich A, Battaglia R, Kooiker M, Borghi L, Ditta G, Yanofsky MF, Kater MM, Colombo L: MADS-box protein complexes control carpel and ovule development in Arabidopsis. Plant Cell 2003, 15:2603-2611.

84. Shchennikova AV, Shulga OA, Immink R, Skryabin KG, Angenent GC: Identification and characterization of four chrysanthemum MADS-box genes, belonging to the APETALA1/FRUITFULL and SEPALLATA3 subfamilies. Plant Physiol 2004, 134:1632-1641.

85. Ferrario S, Shchennikova AV, Franken J, Immink RGH, Angenent GC: Control of floral meristem determinacy in petunia by MADS-box transcription factors. Plant Physiol 2006, 140:890-898.

doi: $10.1186 / 1471-2229-10-129$

Cite this article as: Ruokolainen et al., Large scale interaction analysis predicts that the Gerbera hybrida floral E function is provided both by general and specialized proteins BMC Plant Biology 2010, 10:129

\section{Submit your next manuscript to BioMed Central} and take full advantage of:

- Convenient online submission

- Thorough peer review

- No space constraints or color figure charges

- Immediate publication on acceptance

- Inclusion in PubMed, CAS, Scopus and Google Scholar

- Research which is freely available for redistribution 